\title{
A idade um dispositivo. A geração como performativo. Provocações discursivo-desconstrucionistas sobre corpo-gênero- sexualidade.
}

La edad un dispositivo. La generación cómo performatividad. Provocaciones discursivas-desconstrucionistas sobre el cuerpo-género-sexualidad.

Age as a dispositif and generation as performativity.

Deconstructive considerations about body, gender and sexuality.

\section{Fernando Pocahy}

Universidade de Fortaleza (Unifor), Fortaleza, CE, Brasil.

\section{Resumo}

Este ensaio é resultado de (três) trabalhos reunidos na problematização das biopolíticas contemporâneas, tomando o dispositivo da idade nas tramas do gênero e da sexualidade. A reunião destes (três) estudos tem como objetivo provocar olhares desviados sobre juventude e velhice, convocando movimentos de reversibilidade da marcação dos saberes prescritivonormativos sobre a performatividade geracional. O trabalho arrisca tensionamentos e provocações acerca dos movimentos de objetificação do corpo, através da aposta conceitual da idade como um dispositivo e da geracionalidade como performatividade.

Palavras-chave: Gênero, Sexualidade, Geração, Performatividade, Biopolítica.

\section{Resumen}

El presente ensayo resulta de la reunión de (tres) investigaciones que tienen cómo reto la problematización de las biopolíticas en la contemporaneidad, esto a partir del dispositivo de la edad y sus relaciones con género y sexualidad. La reunión de estos (três) estudios tienen como objetivo pensar de modo critico las concepciones de juventud y vejez. Proponemos convocar movimientos de reversibilidad en la marcación de los saberes prescritos-normativos sobre la performatividad generacional. La investigación discute y provoca los movimientos de objectificación del cuerpo, a través del entendimiento del concepto de edad cómo un dispositivo y de la generacionalidad cómo performance.

Palabras clave: Género, Sexualidad, Generación, Performatividad, Biopolítica. 


\begin{abstract}
This paper is the result of (three) researches that aimed to problematize contemporary biopolitics focusing the age dispositif in its possible articulations with gender and sexuality. The reunion of these (three) studies searches to produce different views on youth and ageing and tries to initiate a movement of reversibility against the normative and prescriptive gaze of knowledge on generational performances. The goal of the analysis is to produce a disruption in body's objectification through the conceptualization of age as a dispositif and generation effect as performance.
\end{abstract}

Keywords: Gender, Sexuality, Generation, Performativity, Biopolitics.

"Estilhaça a tua própria medida"

Hilda Hilst

(extraído do poema Alcoólicas)

Este artigo tem como objetivo provocar olhares desviados sobre gerações e diversidade sexual, convocando a(s) Psicologia(s) a um movimento de reversibilidade epistemológica da marca de saber prescritivo-normativo que a(s) acompanha(m). Opero aqui com alguns tensionamentos e provocações acerca de movimentos de objetificação que apontam para as regulações estabelecidas na direção da constituição de uma inteligibilidade do humano, através de uma suposta naturalidade, fixidez e coerência entre corpo(sexo)-gênero-sexualidade/prazer

(Butler, 2005a,b,c,d) e idade/ ou gerações. De modo que me parece estratégico e produtivo pensar de que forma a idade cria condições de inteligibilidade para o que definimos em nossas sociedades ocidentais (pós) modernas como humano através de marcadores sociais de identidade e diferença (Silva, 2007).

Esta aposta encontra-se sustentada na ideia de que o projeto (bio)político que cerca a experiência geracional e algumas das interseccionalidades que acabei de citar, fez não somente da sexualidade um dispositivo, mas também produziu gênero e idade como um conjunto mais ou menos heterogêneo que comportando práticas discursivas e/ou não discursivas de objetivação, através de controle, normatização e regulação das subjetividades.

Deste modo é importante ressaltar o conceito de interseccinalidade, como uma possibilidade de "escarnificação" das malhas discursivas que produzem o corpo como prisioneiro das significações do conceito de humano e vida. Na perspectiva 
de Sirma Bilge (2009) a interseccionalidade remete a uma abordagem transdisciplinar que objetiva "apreender" a complexidade das identidades e das desigualdades sociais, recusando o fechamento e a hierarquização de grandes eixos de diferença social. Nesta concepção, trata-se de ultrapassar o simples reconhecimento da multiplicidade de sistemas de opressão, postulando de outra forma a interação entre estas categorias e a reprodução das desigualdades sociais. De modo que compartilho da premissa de que a idade pode ser pensada como uma categoria política, histórica e contingente como são gênero, classe social, sexualidade ou raça e etnia e de que estes se constituem enquanto sistemas discursivos complexos e, na maioria das vezes, interpedendentes em suas ramificações, senão que consubstanciais.

Estas são as minhas provocações iniciais e desde onde procuro algumas pistas para compreender o que produz inteligibilidade e confere reconhecimento a alguém em termos de "humanidade" na contemporaneidade: o que deve o sujeito contemporâneo à sua idade e quais são as hierarquias produzidas em nosso tempo para a objetificação de discursos de inteligibilidade? $\mathrm{O}$ que pode uma vida com a sua idade? $\mathrm{O}$ que pesa e o que conta a idade que levamos? Pode um sujeito existir - oferecer inteligibilidade social - sem a sua idade? E uma idade pode ser a mesma de uma geração a outra? O que o corpo deve aos regimes políticos na gestão da vida (generificada) e o qual o papel da(s) Psicologia(s) nessa trama discursiva das fases de vida - como a adolescência e/ou juventude?

Seguindo nestas problematizações derivadas de Michel Foucault (2006) sobre a gestão da vida humana, é importante sublinhar que a regulação da vida e a noção de população não podem ser pensada sem a organização e a produção de expectativas para as idades/fases da vida:

"El otro campo de intervención de la biopolitica va a ser todo un conjunto de fenómenos, de los cuales algunos son universales y otros accidentales pero que, por una parte, nunca pueden comprimirse por entero, aunque sean accidentales, y que también entrañan consecuencias análogas de incapacidad, marginación de los individuos, neutralización, etc. Se tratará del problema de la vejez, muy importante desde principios desde siglo XIX (en el momento de la industrialización), del individuo que, por consiguiente, queda fuera del campo de capacidad, de actividad. Y, por otra parte, los accidentes, la invalidez, las diversas anomalías. En relación con estos fenómenos, la biopolitica va a introducir no sólo instituciones asistenciales (que existían 
desde mucho tiempo atrás) sino mecanismos mucho más sutiles, económicamente mucho más racionales que la asistencia a granel, a la vez masiva y con lacunas, que estaba esencialmente asociada a la Iglesia. Vamos a ver mecanismos más racionales, de seguros, de ahorro individual y colectivo, de seguridad, etcétera." (Foucault, 2006 [1976], p. 221)

Para isso, corroborada a ideia pela perspectiva de Pierre Bourdieu (2005[1978]), podemos dizer que estamos diante de uma disputa sobre o domínio dos sujeitos ao limitar a experiência geracional a divisões arbitrárias - erigidas evidentemente a partir de conceitos e práticas regulatórias. Segundo Bourdieu (op.cit.) estas classificações por idade (mas também por gênero, "orientação sexual" e também por classe) remetem-nos sempre à imposição de limites e de produção de uma ordem pela qual cada um deve se fixar, na qual cada um deve se colocar em seu lugar. O que pressupõe certamente medidas e expectativas sobre a vida.

Cabe sublinhar que o regime discursivo do qual a Psicologia é signatária (enquanto ciência moderna) maquina mecanismos discursivo-epistemológicos que não param de se reinventar, reatualizando e ritualizando estratégias de normalização na produção de indivíduos inteligíveis a partir da idade que portam - como experiência indissociável das performances de gênero e como aptidões para o exercício da sexualidade. Essas engrenagens atuam através da reificação das representações de um ideal de humano cercados pelas interpelações e traduções normativas da experiência do corpo.

No plano das hierarquias sexuais e das relações de gênero, essas interpelações se destacam a partir da heterossexualidade compulsória e do seu calendário de reprodução (em que pese as tecnologias reprodutivas) como uma finalidade $\mathrm{e}$ evidência humana. Essa ficção biopolítica é explicitada sobretudo pelas fartas representações e movimentos performativos que são acionados exasperadamente no cotidiano social, expressos em prescrições populares ou acadêmicas que precisam constantemente ser repetidas para a sua "garantia" - como a imposição do regime familista ou das funções parentais como únicas formas de inscrição do sujeito na cultura.

No cotidiano das práticas psi estas objetificações contam com a comoção interdisciplinar de campos de saber normativos e moralidades canônicas, fazendo proliferar em teorias e discursos de autoridade a maquinaria linguística que reforça o que Judith Butler denomina como as vidas que valem a pena serem vividas e as vidas que não importam. 
Persigo em provocação: de que figura de humano estamos tratando na Psicologia quando discutimos infância, juventude, 'velhice' e gênero e sexualidade? O que estamos produzindo em nossas práticas psi quando preterimos a plasticidade cultural e a força política aos modos normativos de estruturação do sujeito? Qual o status ontológico (a investigação teórica do ser) dessas figuras de humanos que estamos tentando definir como vidas que importam? E como nós nos posicionamos, enquanto intelectuais e/ou profissionais da Psicologia, diante das formas de governo dos indivíduos que passam pela "gestão das idades"? Que papel a Psicologia exerce nesse projeto de gestão da vida e quais são as possibilidades de resistência que somos capazes de produzir em nossas práticas? Qual é a margem de liberdade que podemos abrir nos jogos de exclusão e de reificação de figuras normativas com nosso fazer "etarizado"? O que pretendemos quando dizemos que algo ou alguém é normal do ponto de vista das performances de gênero e da diversidade sexual? Qual a força da Psicologia na contestação das formas de regulação da vida diante de posições de gênero, raça/etnia, sexualidade, classe social?

Essas são interrogações que podem nos fornecer algumas pistas sobre os modos como se engendram e como se materializam os regimes discursivos em torno da coerência corpo-gênerosexualidade. Estas inquietações nos permitem também revisitar a/s Psicologia/s. Afinal, quais são as marcas obrigatórias que devemos portar para acedermos a posição de um sujeito possível socialmente, o que é necessário aparentar, ser, dizer, para que alguém ou alguma relação seja considerada como socialmente reconhecida nessa perspectiva do sujeito dito normal ou "saudável" para a Psicologia?

\section{As muitas densidades de uma geração: juventude e velhice como performatividade.}

Ensaiando alguma intimidade com problemas que se desmancham no jogo das ditas aparências (pós)-modernas, tenho me ocupado em buscar possibilidades de imaginar/viver uma erótica na cama discursiva das idades da vida, como plano tático para uma genealogia das moralidades que cercam o corpo, o gênero e a sexualidade nas suas intersecções geracionais. Procuro compreender o corpo jovem ou idoso desde a perspectiva de uma materialidade que encarna e desencarna e torna a encarnar os discursos que evidenciam o trabalho incansável, 
inacabável e ficcional das normas biopolíticas.

Este trabalho de pesquisa sobre as idades se localiza particularmente e de forma mais contundente em três investigações realizadas no âmbito dos estudos de gênero e sexualidade em perspectiva interdisciplinar - Psicologia, Educação e Antropologia (Pocahy, 2006, 2011, 2012).

A primeira pesquisa que realizei sobre as formas de regulação da sexualidade na trama discursiva das idades deu-se junto ao Programa de PósGraduação em Psicologia Social e Institucional da UFRGS, em parceria com a ONG nuances - grupo pela livre expressão sexual (a qual estive vinculado por muitos anos enquanto coordenador político e de projetos). Esse trabalho problematizou as experimentações da sexualidade de jovens que se auto identificavam como lésbicas, gueis, travestis, heterossexuais, bissexuais e transexuais e que aderiram a uma ação de saúde no campo das doenças sexualmente transmissíveis/ hiv e aids. Além de seu caráter de enfrentamento à epidemia, a intervenção permitiu uma análise sobre os modos como alguns jovens produzem experimentações na sexualidade face à homofobia presente na sociedade brasileira (Pocahy \& Nardi, 2007).
O estudo citado foi orientado metodologicamente pela perspectiva da pesquisa-intervenção （Maraschin， 2004; Aguiar \& Rocha, 2003) e os seus resultados apontaram para alguns dos limites e das possibilidades das ações de saúde junto ao público juvenil. A ação buscou transformar as condições de vulnerabilidade, explorando as possibilidades de deslocamento de uma posição abjeta para a de cidadão de direitos, pela via da reflexão e da ampliação das redes de sociabilidade, especialmente tecidas na perspectiva da homo/eroti/cidade. Este efeito foi buscado principalmente na formulação de estratégias coletivas de enfrentamento das capturas identitárias ligadas à estigmatização da pobreza na sua associação com as sexualidades ditas marginais, sem perder de vista as formas de resistência e contestação agenciadas nas práticas e experimentações da sexualidade/eroticidade.

$\mathrm{Na}$ continuidade das inquetações a respeito da força do regime discursivo que cerca as gerações, associado a uma lacuna nos estudos sobre homo/erotismo e envelhecimento masculino, ocupei-me em minha pesquisa de doutorado junto ao Programa de Pós-Graduação em Educação na Universidade Federal do Rio Grande do Sul (UFRGS) em buscar por 
experimentações 'desobedientes' de uma sexualidade e de um corpo "dissidente" (Halperin, 2000): deriva deste estudo de tese a constatação de algumas possibilidades de sociabilidade que permitem aos idosos a contestação do destino de uma sexualidade 'bizarra' e como corpos fora do 'mercado do sexo'. Através de performances desempenhadas com (algum) prazer, com (alguma) invenção, com (algum) tesão, com (alguma) graça e com (algum) desafio de si e, com alguma intenção, acompanhei algumas narrativas e experimentações situadas, situacionais e efêmeras - de um 'corpo' dito 'menor' em uma cena dissidente.

Seguindo as pistas que desenhavam uma imagem aproximada para um idoso, a partir de um terreno escorregadio de zonas de experimentação orgiástica (saunas, bares de prostituição, etc), pude acompanhar uma imagem provisória deste idoso ocupando um lugar possível na cidade, que em seus movimentos de erotismo 'deformam' as representações 'normais' para o dito corpo 'desejável'. Isso me permitiu afirmar que outra cena de erotismo é possível e que ela vai se definindo no instante da sua própria experimentação, recusando e/ ou negociando com as interpelações do seu traçado político - afinal, a sexualidade é política. O que pude acompanhar durante minha pesquisa de doutorado foi um instante de algo produzindo um esboço da experiência política da corporal/idade.

A partir de estudos em Michel Foucault e de Judith Butler (entre outras teóricas feministas lésbicas e/ou queer), procurei especialmente nos dois trabalhos citados acima (dissertação e tese) compreender como as normas instituem um regime de gênero e de (homo)sexualidade, a partir da idade e das representações sobre o envelhecimento e juventude. E, embora não traga nenhuma novidade dizer que as normas governam os discursos, cabe recapitular que elas produzem e regulam o sujeito do discurso, fazendo a vida (corporal) dos indivíduos (Butler, 2004), habitando os corpos (no caso do protagonista desta pesquisa, a materialidade discursiva o corpo 'idoso' / o corpo 'velho'). Meu interesse deitou-se com estas ideias e procurou, desde um trabalho discursivo-desconstrucionista (particularmente considero nesta perspectiva os trabalhos Judith Butler, Gayle Rubin, Teresa de Lauretis, Guacira Lopes Louro, Marie-Hélène Bourcier e Beatriz Preciado), ensaiar alguma intimidade com movimentos na homo/eroti/cidade que pudessem indicar formas de contestação ou resistência à norma geracional. Minha provisória 
certeza guia é/foi de que as experimentações das sexualidades ditas 'minoritárias'(Louro, 2004), indóceis, dissidentes ou desobedientes, podem evidenciar algo dos jogos discursivos que encarnam o corpo, entre as continuidades e descontinuidades habilitantes do gênero e da sexualidade, demonstrando o seu caráter ficcional/ fabricado.

A partir deste arranjo, pondero que as práticas sexuais e eróticas podem perturbar o gênero (Louro, 2004) desde o interior de sua produção discursiva, desestabilizando os instituídos que 'evidenciam' as 'identidades' 'gênerosexualizadas'. De alguma forma, as práticas sexuais produzem desarranjos nas representações. Mas, acredito que elas dizem pouco ou quase nada sobre os sujeitos em si mesmo. E considero que os sujeitos presentes nestes estudos foram interlocutores de cenas e de instantes que rasgaram uma cena particular, em uma das telas da moral que cerca o corpo generificado e os prazeres sexuais - a tela das representações sociais. Cabe recordar aqui o sentido atribuído a representação segundo Tomaz Tadeu da Silva:

"No contexto dos Estudos Culturais, a análise da representação concentra-se em sua expressão material como 'significante': um texto, uma pintura, um filme, uma fotografia. Pesquisam-se aqui, sobretudo, as conexões entre identidade cultural e representação, com base no pressuposto de que não existe identidade fora da representação" (2000, p.97).

E, embora eu não tenha encontrado potencialidades contundentes na desestabilização do gênero, mesmo diante das desobedientes formas de experimentação da sexualidade que tive a oportunidade de acompanhar nestes estudos, as imagens das 'fechações' de terreno (as performances dos sujeitos, a 'perform/ação' de um discurso e os movimentos destes diante das bricolagens de significados estéticos para a sexualidade) ofereceram-me possibilidades de abrir a reflexão sobre o teatro da heterossexualidade compulsória e os pocket shows cotidianos das hetero $\mathrm{e}$ homonormas (esta relacionada às formas de experimentação normativas das sexualidades LGBT), correspondem à reiteração da norma corpo-gênerosexualidade (e idade, entre outras interseccionalidades), como forma de manter a ordem heterossexual (Pocahy \& Nardi, 2007).

Cabe sublinhar que, no seu esforço de

$$
\text { desnaturalização }
$$
gênero/sexualidade/desejo, Judith Butler (2005a) denuncia a fragilidade constitutiva da heterossexualidade pelo seu próprio avesso, afirmando que as práticas sexuais 
ditas não normais colocam em xeque a estabilidade do gênero (por exemplo, o regramento ativo-masculino versus passivo-feminino) na definição do que é ou não "normal" e por isso possível, em termos da sexualidade e de uma vida inteligível.

Além disso, considerando a idade como dispositivo importante no jogo das 'aparências' e nas formas de performativizar o gênero persegui/go a questão e/ou problemática sobre uma erótica para as gerações, como experiência instituída em atos performativos. Isto é, a partir de determinadas condições de possibilidade produzem perfurações nas representações que n/os produzem/exibem/projetam como vidas “abjetas" (Butler, 2000 [1993], 2004a, 2005a [1990], 2006d [1993]), no mesmo instante em que temos a possibilidade de arriscar alguma resistência e alguma resignificação. Segundo a autora (op. cit.) a performatividade "não é simplesmente uma prática ritual: é um dos rituais maiores pelos quais os sujeitos são formados e reformulados" (2004 [1997], p.247).

Avançando nesta reflexão, desenvolvi através de pesquisa de pósdoutorado "'Botando corpo, fazendo gênero'. Representações e práticas de estetização na (re)definição corporal de masculinidades juvenis (entre estudantes de ensino médio de escolas públicas na Grande Florianópolis ${ }^{1}$, estudo que buscou compreender, a partir das experimentações de jovens no âmbito da educação escolar, como algumas dentre as linhas dos regimes discursivos que trabalham na produção normativa das masculinidades e dos dispositivos que as interpelam, cercam e (re)definem como importantes elementos para a reflexão sobre pedagogias de gênero e de sexualidade (Louro, 2004) na educação escolar.

Nesse trabalho de pesquisa se revela certo pragamatismo e intencionalidade contundente (não que não haja implicação e engajamento político nos anteriores), no sentido em que através da perspectiva da pesquisa-intervenção busquei subsídios para o fomento e a (re)formulação de políticas públicas em Educação na direção da diversidade cultural e social das infâncias e das juventudes, em sua articulação com gênero e sexualidade, no mesmo instante em que ensaiamos alguma reversibilidade tática destas marcas de poder.

Atualmente sigo com inquietações geracionais e sobre a maquinação etária nos regimes de regulação do corpo e dos prazeres. Para isto, desenvolvo uma quarta pesquisa, intitulada "Retratos-narrativas do envelhecimento entre a população LGBTI em Fortaleza: um estudo sobre 
sociabilidades, violência e políticas públicas", junto ao Programa de PósGraduação em Psicologia da Universidade de Fortaleza. O projeto analisa formas de regulação do gênero e da sexualidade em sua articulação com a produção discursiva do envelhecimento, como forma de compreensão dos processos de vulnerabilidade entre a população LGBT, buscando problematizar os discursos que se encontram em negociação nas experimentações da sexualidade desta população; onde o problema principal de estudo refere-se aos os modos como a população LGBT envelhece, quais são as representações sobre corpo, gênero e saúde que cercam suas experimentações e como estas são negociadas e vividas desde contextos culturais discriminatórios. Objetivo com o estudo citado é de compreender-intervir sobre a vulnerabilidade social entre uma população posicionada/produzida diante dos jogos discursivos que marcam as normas sexuais em suar articulação com envelhecimento. Esta pesquisa é uma dos sub-projetos vinculados à pesquisa "Gênero e sexualidade em interseccionalidades: problematizando processos de subjetivação e educação", projeto guarda-chuva do Laboratório de Estudos e Pesquisas Multiversos - Processos de Subjetivação,
Educação e Sexualidades - PPG Psi Unifor.

Destas perfurações ou rasgos discursivos ou de suas formas de assujeitamento e objetificação materializados em práticas e representações sobre as quais venho me aproximando na pesquisa, aposto na ideia de que não podemos pensar em identidades sexuais ou identidades de gênero fora de uma norma, uma vez que elas são em si mesmas a marca indelével de um dispositivo que é articulado sempre através de outros dispositivos.

De outra parte, pergunto-me sempre se não podemos dizer que se instaurariam à revelia de qualquer pragmática ou programa político para gênerosexualidade-gerações-etnias movimentos de contestação e de ruptura nos jogos da abjeção. Dessa forma, ponderando as possibilidades e os limites que essa perspectiva de tomar a idade como dispositivo e as gerações como performatividades, arrisco dizer que uma das formas possíveis de contestação à norma que estabelece a heterossexualidade como referente de inteligibilidade 'incontestável' é (re)feita no interior dessas interpelações; onde os sujeitos dizem algo sobre si em gestos, em narrativas e na organização, autoestetização e 'cenarização' dos espaços onde se inserem, 
articulando (performando) representações produzidas em jogos performativos.

Portanto, cabe dizer que se somos um tipo de efeito de discursos produzidos em jogos de saber-poder, não significa que estamos negando a evidência do que nos faz seres vivos - vísceras, membros, pele, órgãos dos sentidos, etc. É justamente a ideia de 'natureza irredutível' que faz do corpo uma superfície contundente no engendramento de terminados jogos de verdade, como aqueles jogos da produção do regime discursivo que instituem a sexualidade como um mecanismo de poder - "ao mesmo tempo um mecanismo de saber, de saber dos indivíduos, saber sobre os indivíduos, mas também saber dos indivíduos sobre eles mesmos e quanto a eles mesmos" (Foucault, 2001a [1978], p.566).

O conceito de "jogos de verdade" é fundamental nessas problematizações e ele corresponde, segundo Foucault (2001b [1984]), à relação que os sujeitos podem estabelecer consigo mesmos, através de certo número de técnicas e regras - os jogos de verdade - que os constituem como um sujeito (inteligível/reconhecível). De onde uma problematização sobre os jogos de verdade, corresponderia, portanto, e nos termos do autor citado, a uma forma de compreensão sobre as condições às quais 'os sujeitos' estão submetidos. Isto é, qual estatuto se assume, qual posição se pode/deve ocupar, no real ou no imaginário, para tornar-se 'sujeito' legítimo de tal ou qual (re)conhecimento, neste caso, através da interseccionalidade gênero-sexualidade-idade-raça/etnia.

Produzimo-nos como sujeitos reconhecidos socialmente não unicamente pela materialidade visível de nossos corpos, mas pelo traçado discursivo (enunciados discursivos) que ficcionam o corpo como matéria de inteligibilidades engendradas em idade, aparência corporal, classe social, gênero e sexualidade. Logo, se eu interrogo os sistemas/regimes de verdade, eu me interrogo sobre a minha própria constituição e ontologia (Butler, 2006), isto é, sobre meu próprio status ontológico. Como aponta Foucault (2001c [1977]):

\footnotetext{
"Se o poder atinge o corpo, não é porque ele foi interiorizado inicialmente na consciência das pessoas. Existe uma rede de biopoder, somato-poder, que é em si mesma uma rede a partir da qual nasce a sexualidade como fenômeno histórico e cultural, no interior do qual, às vezes, nos reconhecemos e nos perdemos.” (p. 231)
}

Nesse sentido, caberia ainda perguntar qual seria mesmo o corpo re/clamado pelo movimento feminista ou LGBT e queer, enquanto instâncias 
privilegiadas na contestação das normas e hierarquias sociais, quando se proclama a fortes vozes "meu corpo me pertence", de que corpo se trata? Como sugere Lagrave (2009): que vozes reivindicativas se escutam quando o corpo oferece os primeiros sinais de "decrepitude" e de "partida", no jogo de oposições geracionais - juventude e velhice? Afinal, de que corpo se fala e qual corpo se reivindica nas políticas de identidade? Que corpo e que práticas importam para as lutas das “identidades" minoritárias?

\section{Ficções no/do corpo}

Como fabricação discursiva na produção performativa que faz um arranjo particular entre oposições, descontinuidades e continuidades na trama infância, juventude, 'adultez,' velhice, gênero e homo/sexualidade, a idade que levamos é uma dentre as formas de inteligibilidade ao que pode ser considerado como uma vida possível, mas sempre socialmente reguladas por engajamentos políticos institucionais e arranjos culturais. Desta forma, estamos diante de um agenciamento discursivo que não faz outra coisa além de tentar situar o sujeito de forma reconhecível e como um sujeito que possa ser 'citado' - que produz experimentações de si desde performatividades - como sujeito possível ou pensável.

Ao aproximar-me à ideia de movimentos de citação e de recitação performativas, que tornam inteligível um corpo/sujeito, não posso deixar de pensar nos sentidos para a vida que um corpo é capaz de encarnar; e por isso interesso-me em compreender como o corpo oferece-se a (e/ou como ele desestabiliza) estes processos, como no envelhecimento, por exemplo.

E ao reencontro das ideias de Lagrave (2009), concordo que "questionar uma ordem das idades é uma maneira de reencantamento, no sentido em que interrogamos, sob novos riscos, as evidências tributadas à velhice, realocando os recursos cognitivos e políticos inusitados cruzando os efeitos recíprocos entre a ordem dos gêneros e das idades" (2009, p. 113).

Por isso, reforço, compreendo a idade como uma categoria política, histórica e contingente, assim como o gênero, a classe social, a sexualidade ou a raça/etnia. Mas, não de forma isolada, pois o marcador etário e geracional dificilmente pode ser pensado sem essas intersecções. $\mathrm{O}$ que significa dizer que a idade organiza a vida, ao conferir status de 'humanidade', em diferentes formas e condições políticoculturais no mesmo instante em que gênero 
e sexualidade tornam-se visíveis e possíveis nesta trama discursiva (ao fixar as possibilidades para cada idade da vida). Essa é uma das tramas presentes no projeto moderno.

De fato, esta constatação não traz nenhuma novidade. No entanto, pareceume estratégico pensar como a idade cria condições de inteligibilidade para o que construímos em nossas sociedades ocidentais (pós) modernas como humano e como gênero e sexualidade se articulam nesse projeto (bio)político do corpo moderno.

O corpo pleno, veloz, dinâmico é o corpo da utopia biopolítica do projeto moderno, um corpo que não chega a ser alcançado. É um corpo 'planejado', desenhado, calculado, medido, ficcionado. O corpo é uma ficção política, forjada, tecida em dispositivos de gênero, sexualidade, idade, tamanho, forma, peso, 'raça'...

Mas outro corpo seria possível? Chego a acreditar que sim. Talvez aquele corpo presente na cena da forclusão da erótica moderna, no interior de uma cena que toma modos de uma resistência pelos seus atos de contestação e que oferece outro corpo ao corpo - como unicamente um topos, uma superfície sem fundo e sem medida.
"Meu corpo é o contrário de uma utopia (...) ele é o lugar absoluto, o pequeno fragmento de espaço com o qual em um sentido estrito eu faço corpo". Essa frase de Michel Foucault (2009, p.10), presente em uma radioconferência de 1966, publicada em Le corps utopique. O texto inquieta. Afirma Foucault: uma utopia é um lugar fora de todos os lugares. É uma promessa. É onde também podemos pensar em um corpo incorporal. Ele afirma: "a utopia é um lugar fora de todos os lugares (...) é um lugar onde eu teria um corpo sem corpo, um corpo que seria belo, límpido, transparente, luminoso, veloz, colossal em sua potência, infinito em sua duração, suspenso, invisível, protegido, infinitamente transfigurado (...) utopia de um corpo incorporal"'(2009, p.10).

O corpo, eu arrisco dizer, pode ser também uma heterotopia - uma heterotopia de si como refúgio da normal-IDADE. Em suas superfícies, formas, sentidos e prazeres, o corpo faz dele um lugar outro, tomado em um instante de orgia ou instante de uma cena de exceção. Como afirma Foucault (2009), talvez seja por isso que (alguns dentre nós, eu diria) gostemos tanto de fazer sexo: porque no sexo o corpo é aqui. 


\section{Provocações inconclusas para uma psicologia menor}

Muitas inquietações e algumas idéias ardidas para re-começar em outro lugar - talvez a Psicologia ou as psicologias também como heterotopias. Precisamos tomar uma posição diante das formas de hierarquização e da patologização do gênero nas psicologias, compreendendo que nosso modo de conhecer e as práticas que se produzem destes modos são sempre marcadas por formas normativas em performances de gênero e no exercício da sexualidade, interpeladas em fases de vida - que mortificam a experiência e a potência do corpo lambido linguisticamente pelas ondas geracionais.

A Psicologia como movimento político-epistemológico deve nos conduzir a um compromisso ético. $E$ isto inclui pensar as tramas discursivas que cercam a sexualidade e o gênero em suas interpelações geracionais, como as juventudes e as formas de envelhecer. Nós precisamos refletir muito e constantemente sobre o papel que exercemos como operadoras e operadores psi e que tipo de epistemologia do mundo estamos construindo ou reproduzindo, enquanto signatárias/ros de um campo de saber produzido nas injunções modernas acionadas no dispositivo da sexualidade e de controle da vida. Mas, além disso, pensar sobre nossas práticas cotidianas, nossas ferramentas conceituais, nosso posicionamento enquanto sujeitos interpeladas/interpelados em posições de gênero e sexualidade, raça, etnia, classe social e idade, entre outros marcadores de produção de diferença (e de quando a diferença se torna desigualdade social). Interrogarmo-nos sobre o que estamos fazendo de nós mesmos e tentando fazer dos outros já nos ajuda no exercício de políticas desobedientes para a Psicologia, no exercício das psicologias como práticas reflexivas da liberdade (Foucault, 2001d,e [1984]).

É quase certo para mim que temos a chance de contestar nossa herança (disciplinar e) normativa, fazendo um trabalho de "criação de lugares que resistem, minam e removem as formas de opressão institucionalizadas" (Roffes, 2007, p.110), problematizando - e isto já pode significar intervir - sobre os efeitos de normalização, em qualquer tempo da vida e quaisquer que sejam as formas e sentidos que se deem ao corpo.

O corpo sequestrado das disciplinas e das moralidades canônicas pode ser, de alguma forma, devolvido ao corpo. E, recusando por instantes as suas medidas e supostas inteligibilidades, denuncia a alma 
como a sua prisão, já nos diria Foucault (1996 [1975]).

\section{Notas}

1 Pesquisa associada à ação PROEXTENSAO "Projeto Papo sério", desenvolvida pelo Núcleo de Identidades de Gênero e Subjetividades NIGS/Programa de Pós-Graduação em Antropologia Social da Universidade Federal de Santa Catarina - UFSC, sob a coordenação da Professora Dra. Miriam Pillar Grossi. O Projeto Papo Sério tem como objetivos a pesquisa e o enfrentamento às violências de gênero e 'lgbtqi-fobias' no campo da educação escolar. Minha pesquisa de pós-doutorado foi realizada junto ao NIGS/ PPGAS entre março de 2011 e fevereiro de 2012.

\section{Referências}

Aguiar, K. \& Rocha, M. L. (2003). Pesquisa-intervenção e a produção de novas análises. Psicologia, Ciência e Profissão, 23 (4), pp.64-73.

Bilge, S. (2009). Théorisations féministes de l'intersectionnalité. Diogène, 225 (jan-mar), 70-88.

Bourdieu, P. (2005). La « jeunesse » n'est qu'um mot. Entretetien avec AnneMarie Métailié,paru dans Les jeunes et le premier emploi. Disponível em:www.hommemoderne.org/societe/b ourdieu/questions/jeunesse.html.

Acessado em 12/12/2005.(Original publicado em 1978).

Butler, J. (2006). Défaire le genre.Paris: Éditions Amsterdam. (Original publicado em 2004).

Butler, J. (2005a). Trouble dans le genre. Pour un féminisme de la subversion. Paris: La Découvert. (Original publicado em 1990).

Butler, J. (2005b). Humain, inhumain. Le travail critique des normes. Entretiens. Paris: Éditions Amsterdam.

Butler, J. (2005c). Le récit de soi. Paris: Editions PUF.

Butler, J. (2005d). Cuerpos que importan. Sobre los limites materiales y discursivos del sexo. Buenos Aires/Barcelona/Mexico: Paidós. (Original publicado em 1993).

Butler, J. (2004). Le pouvoir des mots. Politique du performatif. Paris: Éditions Amsterdam. (Original publicado em 1997).

Butler, J. (2000). Corpos que pensam: sobre os limites discursivos do "sexo". In: Louro, G. L. (Organizadora). O Corpo Educado. Pedagogias da Sexualidade. Belo Horizonte: Editora Autêntica. 
Foucault, M. (1996). Vigiar e punir: Nascimento da prisão. Petrópolis: Vozes. (Original publicado em 1975).

Foucault, M. (2006) Defender la sociedad. Buenos Aires Fondo de cultura económica de Argentina. (Original publicado em 1976).

Foucault, M. (2001a). Sexualité et pouvoir. In: Foucault, M. Dits et écrits II, 1976-1988. Paris: Gallimard. (Original publicado em 1978).

Foucault, M. (2001b). Foucault. In: Foucault, M. Dits et écrits II, 19761988. Paris: Gallimard. (Original publicado em 1984).

Foucault, M. (2001c). Les rapports de pouvoir passent à l'intérieur des corps. In: Foucault, M. Dits et écrits II, 1976-1988. Paris: Gallimard. (Original publicado em 1977).

Foucault, M. (2001d). Une esthétique de l'existence. In: Foucault, M. Dits et écrits II, 1976-1988. Paris: Gallimard. (Original publicado em 1984).

Foucault, M. (2001e). L'éthique du souci de soi comme pratique de la liberté. In: Foucault, M. Dits et écrits II, 1976-1988. Paris: Gallimard, 2001.

Foucault, M. (2009). Le corps utopique. Les hétérotopies. Paris: Nouvelles éditions lignes.(Originais publicados em 1966 e 1967).

Halperin, D. (2000). Saint Foucault. Paris: EPEL.

Lagrave, R-M. (2009). Ré-enchanter la vieillesse. Mouvements « La tyrannie de l'âge », 59 (jul-set), pp.113-122. La Découvert, Paris.

Maraschin, C. (2004). Pesquisar e intervir. Psicologia e Sociedade, 16(1), pp. 98-107.

Louro, G. L. (2004). Um corpo estranho. Ensaios sobre sexualidade e teoria queer. Belo Horizonte: Autêntica.

Pocahy, F. A. (2006). A pesquisa fora do armário: ensaio de uma heterotopia queer. Dissertação de Mestrado. Programa de Pós-Graduação em Psicologia Social e Institucional, Universidade Federal do Rio Grande do Sul - UFRGS, Porto Alegre, RS.

Pocahy, F. A. (2011). Entre vapores e dublagens. Dissidências homo/eróticas nas tramas do envelhecimento. Tese de Doutorado. Programa de Pós-Graduação em Educação, Universidade Federal do Rio Grande do Sul - UFRGS, Porto Alegre, RS.

Pocahy, F. A. (2012). "Botando corpo, fazendo gênero". Representações e práticas de estetização na (re)definição corporal de 
masculinidades juvenis (entre estudantes de ensino médio de escolas públicas na Grande Florianópolis). Relatório de Estágio de Pós-Doutorado. Programa de PósGraduação em Antropologia Social, Universidade Federal de Santa Catarina, Florianópolis, SC.

Pocahy, F. \& Nardi, H. C. (2007). Saindo do armário e entrando em cena: juventudes, sexualidades e vulnerabilidade social. Revista Estudos Feministas, 7, pp. 45-66.

Roffes, E. (2007). Transgressão e o corpo localizado: gênero, sexo e o professor homossexual. In: Talburg, S. \& Steinberg, S. R. Pensar queer: sexualidade, cultura e educação. Mangualde: Edições Pedago.

Silva, T. T. (2000). Teoria Cultural e Educação - um vocabulário crítico. Belo Horizonte: Autêntica.

Silva, T. T. (2007). A produção social da identidade e da diferença. In: Silva, T. T. (org.). Identidade e diferença. A perspectiva dos estudos culturais. Rio de Janeiro.

Fernando Pocahy: Professor do Programa de Pós-Graduação em Psicologia da Universidade de Fortaleza (Unifor), onde coordena o Laboratório de Estudos e Pesquisas Multiversos - Processos de

Subjetivação, Educação e Sexualidades. Doutor em Educação e Mestre em Psicologia Social e Institucional pela Universidade Federal do Rio Grande do Sul - UFRGS, realizou pós-doutorado junto ao Programa de Pós-Graduação em Antropologia Social da Universidade Federal de Santa Catarina - UFSC.

E-mail:pocahy@uol.com.br 